screening programmes. It is tempting to speculate that if more districts had done this some of the superfluous activity would already have been curtailed.

1 Ministry of Education. The health of the school child: fifty years of the school health service. London: HMSO, 1958. (Report of the chief medical officer.)

2 Wilson JMG, Junger G. Principles and practice of screening for disease. Geneva: WHO, 1968. (Public health paper, No 34.)

3 Blum HL, Peters HB, Bettman JW. Vision screening in elementary schools. The Orinda study. Berkeley and Los Angeles: University of California Press, 1959.
4 Goss DA, Winkler RL. Progression of myopia in youth. Age of cessation. Am $\mathcal{J}$ Optom Physiol Opt 1983;60:651-8.

5 Stewart-Brown S, Butler NR, Haslum M. Education attainment of children with treated and untreated visual defects. Dev Med Child Neurol 1985;27: 504-13.

6 Bremner MH. Visual acuity in primary school children aged 4-12 years. A review of amblyopia treatment in this age group. Australian foumal of Ophthalmology 1984;12:395-9.

7 Ingram RM. Amblyopia: the need for a new approach. $\mathrm{Br} f$ Ophthalmol 1979;63:236-7.

8 Hill AR. Defective colour vision in children. In: Macfarlane A. Progress in child health. Vol 1. London: Churchill Livingstone, 1984.

(Accepted 22 September 1988)

\title{
The Enniskillen bomb: a disaster plan
}

\author{
M G Brown, S G Marshall
}

\section{Introduction}

On Sunday 8 November 1987 at 1040 am a bomb exploded in Enniskillen at the Cenotaph before the start of the Remembrance Day parade. The site of the explosion was less than a mile $(1.6 \mathrm{~km})$ from this hospital. As a direct result of the bomb 11 people died and 54 were injured. We discuss the overall management of the incident in relation to evacuation of casualties and treatment at this hospital.

\section{The hospital}

Erne Hospital is an acute district hospital with 213 beds and serves a population of 55000 . It is part of the acute general hospital services to the western area of Northern Ireland, which has a population of 225000 . The area hospital (400 beds) is situated in Londonderry at Altnagelvin 65 miles (104 km) away. Belfast is 90 miles $(144 \mathrm{~km})$ from Enniskillen.

The surgical department has an allocation of 70 beds

Erne Hospital, Enniskillen,

Northern Ireland

M G Brown, FRCS, locum senior registrar

S G Marshall, FRCS, registrar

Correspondence to: $\mathrm{Mr} \mathrm{M} \mathrm{G}$ Brown, Department of Surgery, Queen's

University, Institute of Clinical Science, Belfast BT12 6BJ.

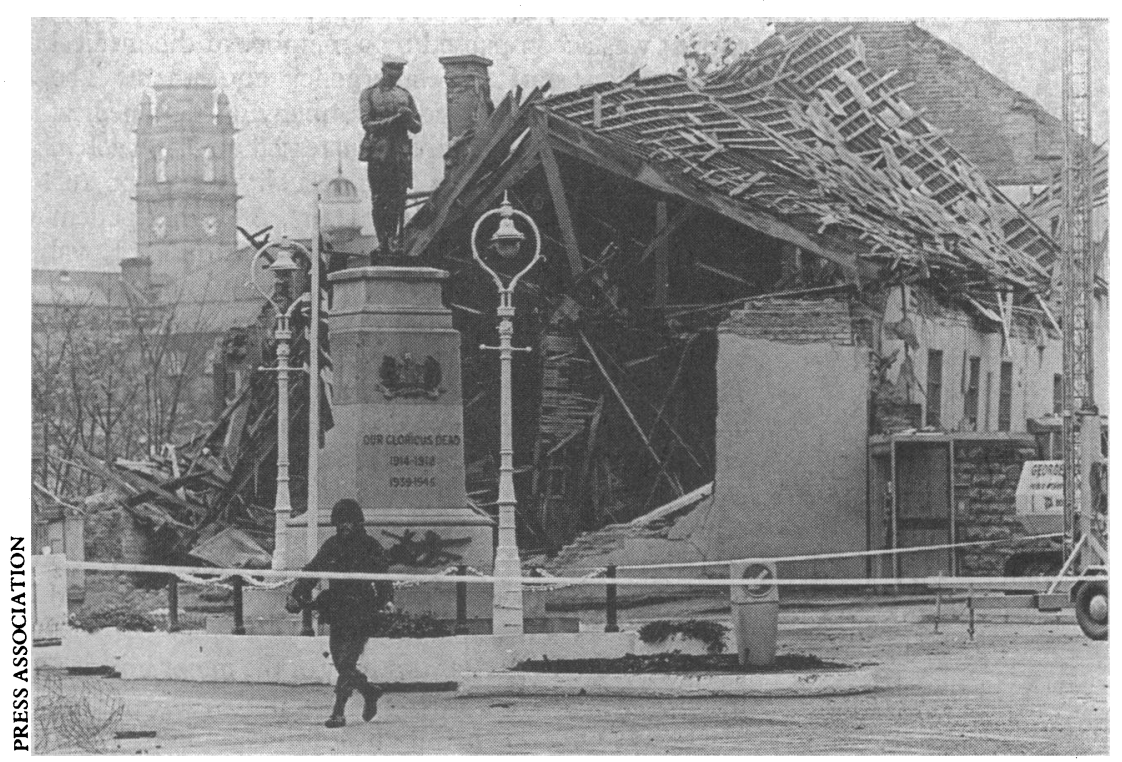

FIG $1-$ Bomb site patients for cardiothoracic surgery, major orthopaedic or plastic procedures, major faciomaxillary procedures, or complicated spinal and head injuries to specialist units in Londonderry or Belfast.

\section{STAFF}

At the time of the bomb explosion the following surgical staff were in the hospital: a locum senior surgical registrar (one consultant was on sick leave), a senior house officer covering casualty, and a preregistration house officer. One staff nurse and a plaster orderly were on duty in the casualty department.

RESPONSE

The explosion occurred at $1040 \mathrm{am}$; ambulance control at the hospital received a 999 call at 1045 . The duty ambulance, of which there is normally one at weekends, was immediately dispatched and arrived at the scene at 1049 . A second ambulance was dispatched at 1050 after the crew had reported in. There were also two minibus ambulances available in Enniskillen which collected patients with minor injuries. One of the two duty ambulances from Omagh $(28$ miles $(45 \mathrm{~km})$ from Enniskillen) was requested to attend the scene. The first patients arrived at the casualty department at 1103 am

Many wounded people made their own way to hospital. A Territorial Army minibus that was at the Cenotaph was also used.

THE SCENE

The explosion occurred in the youth club building (fig 1), which overlooks the Cenotaph, before the annual Remembrance Day parade. Many spectators had gathered outside this building and stood beside the gable wall before the parade. The explosion caused the gable wall to be blown out over the spectators (fig 2). Those who were killed or seriously injured were nearest the gable wall.

The only trained personnel initially at the scene were an army paramedical officer, off duty nurses, and a senior member of the ambulance service. The ambulance man acted as incident officer to liaise with ambulance control when the first ambulance arrived at the scene. Further medical staff, a consultant anaesthetist, and a surgical senior house officer were sent to the scene from the hospital. They set up intravenous lines and gave analgesia to seriously injured people and to those who were buried in the rubble. The members of the armed forces and Royal Ulster Constabulary and uninjured spectators helped to dig survivors and bodies from the rubble. The last of the injured people were removed from the site at about $1240 \mathrm{pm}$. 


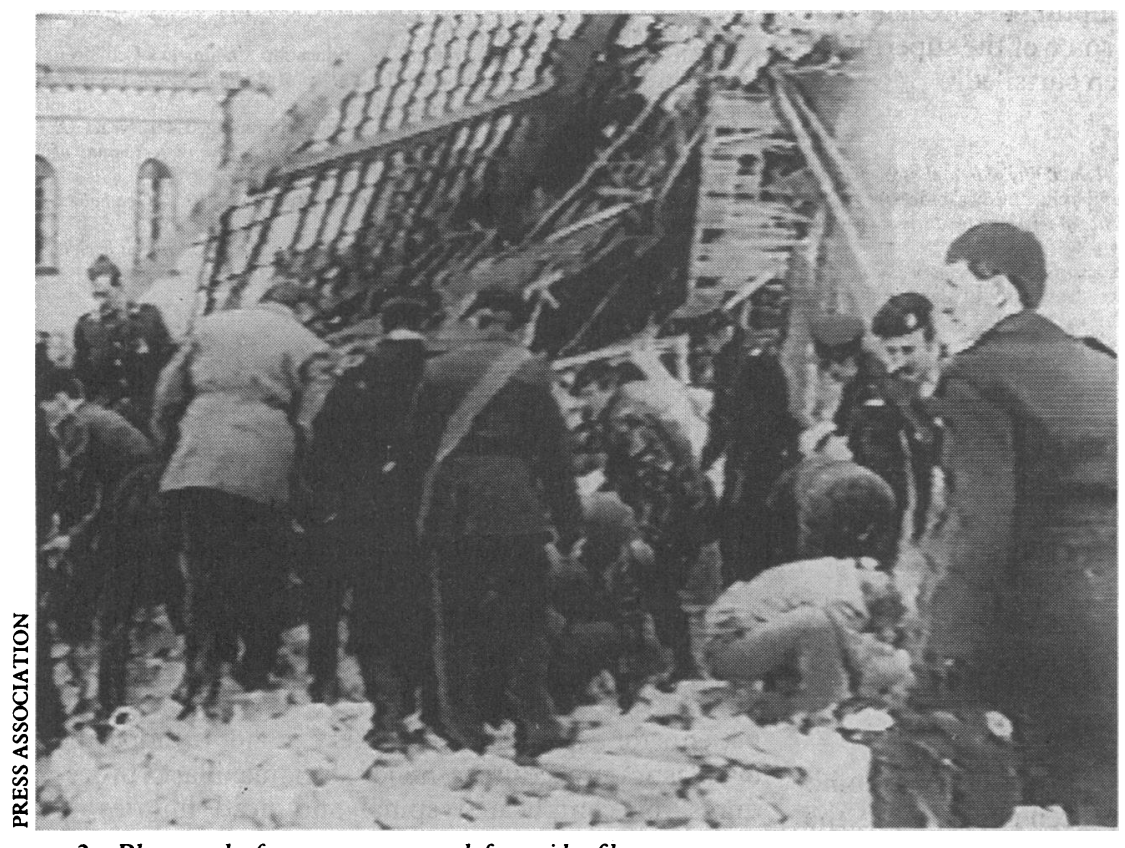

FIG 2-Photograph of rescue teams at work from video film

\section{CASUALTY DEPARTMENT}

Ambulance control informed the casualty department of the incident upon receiving the 999 call. Immediately the switchboard paged the locum senior registrar to attend. With the arrival of the first patients it became apparent that this was a major incident, and the hospital's disaster plan was put into operation. As it was a Sunday the department was virtually empty as were the adjacent physiotherapy and outpatient departments. Maximum space was initially available for reception of patients. The first casualty arrived at $1103 \mathrm{am}$. Table I lists the available medical and nursing staff at the hospital. A triage was performed by the locum senior surgical registrar. All "walking wounded" were immediately directed to the physiotherapy department. Those who were dead on arrival were taken to a temporary mortuary in the Territorial Army Centre adjacent to the hospital. Seriously

TABLE I-Medical and nursing staff available at the time of the explosion

\begin{tabular}{lc}
\hline \multicolumn{1}{c}{ Medical } & Nursing \\
\hline & Immediately available on site \\
1 senior surgical registrar & 11 staff nurses \\
1 consultant anaesthetist & 3 staff midwives \\
1 surgical senior house officer & 3 enrolled nurses \\
1 surgical junior house officer & 2 student nurses \\
1 medical registrar & 1 nursing auxiliary \\
1 medical senior house officer & \\
1 medical junior house officer & \\
\multicolumn{1}{c}{ Additional help that became available during or after initial casualty reception } \\
1 consultant surgeon & 1 director of nursing \\
2 consultant anaesthetists & 1 assistant director of nursing \\
1 consultant radiologist & 1 chief administrative nursing officer \\
2 consultant physicians & 2 nursing officers \\
1 surgical registrar & 4 sisters (theatre, accident and emergency, intensive care \\
6 senior house officers & unit, surgical ward) \\
4 general practitioners & 15 staff nurses \\
& 7 enrolled nurses \\
& 3 district nursing sisters \\
& 1 health visitor \\
& 1 school nurse \\
& 1 nursing auxiliary \\
\hline
\end{tabular}

TABLE II - Injuries requiring immediate transfer of patient to subspecialty units

\begin{tabular}{ll}
\hline $\begin{array}{c}\text { Sex and } \\
\text { age (years) }\end{array}$ & Injuries \\
\hline M 65 & Le Fort II fractured maxilla \\
M 62 & Open fracture dislocation right ankle; compression fracture T12; fractured left 4th and 5th ribs \\
M 15 & Le Fort II fractured maxilla; fractured palate; fractured nose; comminuted closed fracture left \\
tibia and fibula; closed fracture dislocation left ankle \\
M 15 & Open fracture left tibia and fibula; fractured left superior pubic ramus \\
\hline
\end{tabular}

injured patients were initially allocated to one of the five beds for assessment and resuscitation. When a patient's condition was considered to be stable he or she was moved to a ward. Patients whose condition was unstable remained in the resuscitation area as all available medical staff were concentrated there.

Initial $x$ ray films were taken only in patients who were suspected of having cervical spinal injuries or chest injuries. Full radiological investigation was carried out after the patients were considered to be clinically stable. Lack of space in the casualty department was a serious problem, and many patients had to be treated on the floor. A member of the medical staff and a nurse were allocated to each patient as they passed the triage point. One senior house officer was given the task of administering analgesia to all whom he thought required it. The medical staff gave updates on changes in the condition of their allocated patients to the locum senior registrar to allow further decisions on management to be made.

Most of the injuries were to the face and head, limbs, and chest. One patient who had a cardiac arrest before arriving in the casualty department was successfully resuscitated and transferred to the intensive care bed. Shortly after this she showed signs of intra-abdominal bleeding and required an immediate laparotomy. Unfortunately she died on the operating table from unsalvageable injuries. No other patient required immediate surgery.

By the time most of the severely injured patients had arrived and were being assessed and resuscitated many other members of off duty staff had reported to help (table I). All support staff were available. The local general practitioners opened the nearby health centre to treat patients with minor injuries. This helped enormously in keeping the emergency reception area clear.

\section{Treating and processing patients}

During the triage it became apparent that several patients would require transfer to area hospitals for definitive treatment. This was obvious initially in four cases (table II). At this time the army advised the hospital administrators that helicopters would be available to transport casualties. This was important, as all the ambulances were in use and the transfer of severely injured patients would have been delayed. The roads around Enniskillen were congested with traffic going to and from the hospital as well as being sealed off by the security forces. The decision to move these patients was made only after complete resuscitation and the patient's condition was stable. Each patient was accompanied by a member of the medical and nursing staff and emergency equipment. The army helicopters had no accompanying paramedical staff. Four patients were transferred to Altnagelvin within an hour of attending casualty reception (65 miles (104 km); 25 minutes by air). A further patient was transferred to the neurosurgical unit in the Royal Victoria Hospital, Belfast, after deterioration from a head injury ( 90 miles ( $144 \mathrm{~km}) ; 45$ minutes by air). He was intubated before being transported (table III). Two further patients were transferred later: a woman to the Royal Victoria Hospital's intensive care unit for ventilation after surgery at this hospital and a 15 year old boy to the Belfast City Hospital for internal fixation of a fractured neck of the femur (table III). None of those patients had complications as a result of being taken by helicopter. All other patients were treated definitively on site (table IV).

Tables II to IV give a summary of the major injuries, most of which were of the head, limbs, and pelvis. There was only one major chest injury and one major intra-abdominal injury. This is consistent with blast 


\begin{tabular}{|c|c|c|}
\hline $\begin{array}{l}\text { Sex and } \\
\text { age (years) }\end{array}$ & Injuries & Reason for transfer \\
\hline M 29 & Closed head injury; fractured mandible & $\begin{array}{l}\text { Deterioration in level of consciousness with } \\
\text { lateralising signs }\end{array}$ \\
\hline F 68 & $\begin{array}{l}\text { Multiple bilateral rib fractures; fractured left } \\
\text { clavicle; bilateral pneumothoraces; supracondylar } \\
\text { fracture left humerus; bilateral compound } \\
\text { fractured patellas }\end{array}$ & $\begin{array}{l}\text { Required ventilation after treatment for } \\
\text { wounds and insertion of chest drains }\end{array}$ \\
\hline M 15 & Facial lacerations; fractured right neck of femur & No facility for internal fixation of hip \\
\hline
\end{tabular}

TABLE IV-Patients admitted as casualties and treated in Erme Hospital

\begin{tabular}{|c|c|c|}
\hline $\begin{array}{l}\text { Sex and age } \\
\text { (years) }\end{array}$ & Injuries & $\begin{array}{l}\text { Length of stay in } \\
\text { hospital (days) }\end{array}$ \\
\hline F 21 & Laceration left common iliac vein; disrupted pelvis; crush injury to legs & Died in theatre \\
\hline M 74 & Facial and scalp lacerations; bruising to left thigh & 7 \\
\hline F 16 & Laceration to forehead, knees, left ankle (both parents killed in blast) & 1 \\
\hline M 30 & $\begin{array}{l}\text { Fractured right and left superior pubic rami; bruising to lumbar area, right upper } \\
\text { ribs, and left thigh }\end{array}$ & 12 \\
\hline F 32 & $\begin{array}{l}\text { Closed fracture left ankle; fractured right superior and inferior and left inferior pubic } \\
\text { rami; fracture right ring finger terminal phalanx; lacerations to left calf and foot; } \\
\text { broken teeth }\end{array}$ & 26 \\
\hline M 34 & $\begin{array}{l}\text { Fractured right clavicle; dislocation right acromioclavicular joint; fractured right } \\
\text { index finger; fractured right } 2 \text { nd rib; laceration to left hand }\end{array}$ & 2 \\
\hline F 12 & Right haemotympanum; closed head injury & 6 \\
\hline M 56 & Fractured right acetabulum; multiple lacerations & 32 \\
\hline M 24 & Fractured right superior pubic ramus & 10 \\
\hline F 67 & Right facial nerve palsy; scalp laceration; soft tissue neck injury & 7 \\
\hline M 27 & Fractured bodies L3, L4; collateral ligament disruption right knee; scalp laceration & 17 \\
\hline F 33 & Scalp laceration & 4 \\
\hline F 6 & Penetrating wound right knee & 2 \\
\hline
\end{tabular}

injuries as previously reported. ${ }^{1-3}$ There were no burns as the explosion caused injuries from falling masonry. The minor injuries ranged from uncomplicated fractures of the arms to cuts and bruises and emotional shock. Many patients were treated in the casualty department and the health centre, and several went to Omagh Hospital to avoid congestion at this hospital. It was impossible to document all the minor injuries owing to the numbers arriving at the casualty department.

\section{Discussion}

Many major bomb incidents have been reported and the management of casualties debated. ${ }^{24-8}$ The standard disaster plan for various hospitals has been discussed and some even practised.$^{9}{ }^{10}$ All these articles have dealt with incidents occurring close to area hospitals which offer immediate subspecialty care and access to a large staff. The incident reported here was the first major incident in Northern Ireland to take place close to a district hospital in a small town (population 15 000), furthest from any area hospital in the province. Does this incident offer any new lessons in the management of a large number of casualties?

If the site and the nature of the explosion are known early in the casualty department the type and severity of the injuries can be estimated, ${ }^{9}$ and the subspecialty units that may be needed for the treatment of specific injuries can be warned. Sending medical personnel to the scene of a major casualty has been questioned. ${ }^{29} \mathrm{~A}$ member of our medical staff was sent primarily to warn the hospital of the numbers of casualties. The other main task at the scene for medical personnel is to give analgesia and set up intravenous infusions, but this can easily be carried out by trained paramedical staff. The ambulance staff at present are not trained for this.

The senior surgical registrar was on site and was able immediately to carry out triage. The main resuscitation area at the hospital was kept clear for patients with serious injuries; all those with minor injuries were sent to the physiotherapy unit, and those who were dead on arrival were sent to the temporary mortuary. Patients arrived so rapidly that it was impossible to clear a ward for casualties, and therefore a preregistration house officer was assigned the task of noting the wards to which all injured patients were admitted. When triage had been completed the numbers of medical staff had increased to 20 and the nursing staff from 20 to 40 . This was totally adequate, and the nursing officer in charge correctly refused further offers of help as this would have produced only confusion and overcrowding.

The arrival of "disaster plan" staff at the casualty department was erratic because staff could not be contacted. Most, however, had either heard the explosion or become aware of it from the media reports. Delays in arrival were also caused by traffic congestion and road closures. Thus only one senior member of the surgical staff was on site for the triage period; the second member arrived in the hospital near the end. Until then the decision made was to transfer all seriously injured patients who were thought to require both specialist care and emergency surgery. Only one patient required immediate surgery on arrival at hospital, and this was possible because a second surgeon had become available during the delay in extracting the patient from the explosion site. This allowed the surgeon performing triage to continue clearing the casualty department.

The availability of army helicopters and a purpose built helipad on the hospital site greatly improved the rapid transport of severely injured patients to the relevant area hospital departments. The ambulances would not have been free until $1245 \mathrm{pm}$, and transport times by road would have taken twice as long as by air.

Communication - The time taken to implement the disaster plan was minimal. It was difficult to contact several members of senior staff as they were not at home and paging devices were not carried by off duty staff. The switchboard quickly became jammed by incoming calls, and because there was no ex-directory line outgoing calls to contact staff were delayed. Administrative staff relayed messages to the media as necessary. This worked well and gave the media information as early as possible.

Emotional aspect-After a bomb explosion, apart from those who are physically injured, there are usually many people with psychological injuries such as people at the scene and friends and relatives of those who are killed or injured. The incident in Enniskillen is unique because it took place in a small town where all the medical and nursing staff, apart from one person, lived in and were part of the community, and this put an added strain on staff dealing with the injured.

\section{Conclusions}

(1) Disaster plans are most effective in large area hospitals that have access to large numbers of staff on call at any given time. At least one senior surgeon is required in the casualty department and one in theatre to provide complete surgical cover. Anything less requires the hospital to become a reception and forwarding station. All patients with serious injuries that will require extensive surgery and intensive care should be transferred as quickly as possible to area hospitals that can provide the necessary subspecialty care.

(2) To facilitate these aims, when access is limited by the disaster rapid air transport, if available, should be used to transfer seriously injured patients whose conditions are stabilised to specialist units. The remaining staff may then concentrate on the triage of further casualties. In such a disaster the ambulance service is insufficient to transfer patients to other hospitals as ambulances are already fully mobilised to transport casualties from the disaster site.

(3) An ex-directory telephone line is essential to allow rapid communication outside the hospital. 
(4) The good will of the health care services is paramount in operating any disaster plan.

We thank the following people: Mr A McKibbin, consultant surgeon, Erne Hospital; Major General R J Hodges, Commander Landforces, Northern Ireland; Chief Inspector G G O'Callaghan, Royal Ulster Constabulary, Enniskillen; Miss E Dundas, assistant director of nursing services, Erne Hospital; Mr R Dixon, ambulance officer, Enniskillen; all medical, nursing, and auxiliary staff, Erne Hospital; and the people of Enniskillen.
1 Kennedy TL, Johnston GW. Civilian bomb injuries. Br Med $\mathcal{F}$ 1975;i:382-3. 2 Tucker K, Lettin A. The Tower of London explosion. Br Med $\mathcal{F} 1975$;iii 287-90.

3 Hadden WA, Rutherford WH, Merrett JD. The injuries of terrorist bombing a study of 1532 consecutive patients. Br $\mathcal{F}$ Surg 1978;65:525-31

4 Caro D, Irving M. The Old Bailey bomb explosion. Lancet 1973;i:1433-5.

5 Bradley JEA. Nurse management during the bombing crisis in Birmingham. Nursing Times 1975;71:1186-8.

6 Anonymous. Hospitals and bombs [Editorial]. Injury 1976;3:169-70.

7 Anonymous. Bombs and hospitals [Editorial]. Br Med f 1979;i:506.

8 Holme P. State of emergency: Brighton bomb. Nursing Times 1984;80:16-7.

9 Rutherford WH. Disaster procedures. Br Med f 1975;i:443-5.

10 Patterson C. Explosion: a case study in disaster drills. foumal of Emergency Nursing 1977;3:9-13.

\title{
Prospective randomised study of an orthopaedic geriatric inpatient service
}

\author{
William J Gilchrist, Raymond J Newman, David L Hamblen, Brian O Williams
}

\begin{abstract}
A randomised controlled trial of two management regimens was carried out in women patients over 65 years of age with hip fractures. Ninety seven patients were admitted to a designated orthopaedic geriatric unit and 125 to orthopaedic wards. No difference was observed in mortality, length of stay, or placement of patients between the two groups. More medical conditions were recognised and treated in patients in the orthopaedic geriatric unit group.

It is concluded that designated orthopaedic geriatric units can provide medical care to these patients and should be administered without additional cost.
\end{abstract}

\section{Introduction}

The recent apparent epidemic of hip fractures in elderly women ${ }^{12}$ has led to a greater awareness of the role of the geriatrician in managing these patients in orthopaedic wards. Many centres in the United Kingdom have established formal liaison between the specialties of orthopaedics and geriatrics, and this may be a solution to many of the problems that elderly women patients present.

An orthopaedic geriatric unit was therefore established at Gartnavel General Hospital in February 1983, with 12 existing orthopaedic beds and medical, nursing, and paramedical staff, at no additional cost. After one year's experience of running this service ${ }^{3}$ we designed a prospective, randomised, controlled study to test the efficacy of this approach to managing elderly women patients with proximal femoral fractures.

Department of Geriatric

Medicine, Gartnavel

General Hospital and

University Department of

Orthopaedic Surgery,

Western Infirmary,

Glasgow

William J Gilchrist, MRCP, consultant geriatrician

Raymond J Newman, FRCS, senior lecturer

David L Hamblen, FRCS, professor

Brian O Williams, FRCP,

consultant geriatrician

Correspondence to: Dr W J Gilchrist, Department of

Geriatric Medicine,

Gartnavel General Hospital

Glasgow G12 0YN. directly. The remaining patients were transferred one and a half miles $(21 / 2 \mathrm{~km})$ to the orthopaedic wards in Gartnavel General Hospital for rehabilitation and were entered into the study if they were women over age 65 .

Patients were stratified on the basis of the site of fracture (intracapsular and extracapsular) and randomised to either the orthopaedic geriatric unit or the orthopaedic wards at the time of transfer. A five to four bias was introduced in favour of the orthopaedic wards owing to the larger number of beds there. No patients were excluded from the study after they were transferred.

Patients in the orthopaedic geriatric unit remained under the overall care of the orthopaedic surgical staff. A weekly combined ward round was performed by a geriatrician (consultant or senior registrar), an orthopaedic senior registrar, and the senior ward nurse. A physiotherapist, occupational therapist, and a social worker participated in the case conference that followed. Advice was given on medical problems that arose between ward rounds by consultation with the geriatrician.

The control group had similar nursing cover and access to similar paramedical services but there was no case conference. Referral for any medical problem to the geriatric service was made by letter, and patients in these orthopaedic wards were seen by a different geriatrician from the one on the orthopaedic geriatric unit. Patients did not transfer between the orthopaedic geriatric unit and the orthopaedic wards, and both groups had access to the same hospital facilities.

Information about inpatients was gathered prospectively, and both groups were visited at home three and six months after discharge. Information was collected on a form and stored on microcomputer.

The three outcome indicators discussed in this paper are mortality, length of hospital stay, and placement after discharge. These have been used in other studies. Length of hospital stay is used as an indirect indicator of cost.

We also analysed the medical diagnoses made in each group and the numbers of case records with missing laboratory results. We also report the numbers of patients discharged with abnormal laboratory results or documented clinical findings that ideally should have been further investigated or treated.

Statistical analysis-Mortality, placement of patients, and the numbers of patients with new and "missed" diseases were analysed by $\chi^{2}$ test with Yates's correction. The length of stay was analysed by Wilcoxon's rank sum test. Confidence intervals were calculated for differences in percentages and means. hospitals without facilities for fracture surgery were usually sent back for rehabilitation soon after operation and were excluded from the trial, as were a few patients who made rapid progress and were discharged home 